\title{
Mental Illness, Healthcare, and Homelessness in Mississippi
}

\author{
Tamara Stewart ${ }^{1 *}$ \\ 1 School of Public Health, Jackson State University, Jackson, MS 39213, USA \\ *Corresponding Author: tamara.stewart@hotmail.com \\ Citation: Stewart, T. (2017). Mental Illness, Healthcare, and Homelessness in Mississippi. European Journal \\ of Environment and Public Health, 1(1), 05. https:/ / doi.org/10.20897/ejeph.201705
}

Published: September 3, 2017

\begin{abstract}
Mental illness is prevalent among the homeless population and the rate of mentally ill homeless individuals has increased since deinstitutionalization. There is little information about homeless population mental health and access to mental healthcare. This study sought to describe the mental health status and utilization of mental healthcare services among homeless individuals in Mississippi. This is a cross-sectional study with 3,375 adults participants. There were 58\% males, $42 \%$ females, $45 \%$ Caucasian, $54 \%$ African Americans, and $1 \%$ other minorities (Asian, Indian, and Pacific Islander) at intake into Mississippi United to End Homelessness' (MUTEH) Homeless Management Information System (HMIS) program. The data was collected during the initial screening of homeless individuals. The screening documented mental illness and utilization of healthcare. Frequency tables and Chi-SQ was used to test the relationship between mental illness and utilization of mental healthcare among the homeless in Mississippi. The result of the analysis revealed that $83 \%$ of the chronically homeless individual had a mental illness, and $78 \%$ of the chronically homeless participants were not receiving mental healthcare. Mental health services were successful in connecting mentally ill homeless individuals to mental healthcare in lieu of institutionalization. However, chronically homeless mentally ill individuals struggle with obtaining appropriate care.
\end{abstract}

Keywords: mental illness, homelessness, Mississippi, accessible health care

\section{INTRODUCTION}

"Madness in the streets" or "Deinstitutionalization: A Psychiatric Titanic" vivid words by two authors depicting their views of the move from asylums or mental institutionalization to community care clinics (Isaac and Armat, 1990; Torrey, 2005). The diagnoses and appropriate care of the mentally ill evolved in 1960 and there have been efforts to shift the care of the mentally ill from the traditional institution to community care (Torrey, 2005). The transition in care was slow, and it has not been fully integrated into the public health community. According to the literature, deinstitutionalization made several mentally ill patients to seek community-based care, which often does not include inpatient care (Rossi, 1990). Furthermore, the change in care led to increased homelessness, this became a burden to the country and a serious public health issue (Rossi, 1990). However, according to the World Health Organization the need for mental healthcare does not justify the exclusion treatment programs like institutionalization. According to this report, many individuals in institutional settings can live independently in the community with community mental healthcare services.

World Health Organization (WHO) in 2001 stated that community care treatment was relevant and proved to be substantial; however, community care only works if the target population can access the community care. Mental healthcare is often tailored to the mental health condition. Mental illness is defined as an illness mainly exhibited through "dysregulation of mood, thought, and/or behavior" (Mental Illness, 2016). 
In America, 18.5\% adults experience mental illness each year ("Mental Health By The Numbers", 2017). In Mississippi, 4\% of adults in the state are severally mentally ill according to a 2010 report by the Insatiate for Disability Studies The University of Southern Mississippi.

In the homeless population, mental illness is disproportionately high. In the United States, $20 \%$ of the homeless population has an SMI, and 30\% of the chronic homeless population reports having an SMI diagnoses ("Homelessness and Housing," 2016). SMI diagnoses among the homeless population are extremely high considering that SMI only accounts for 5\% of Americans ("Facts About Mental Illness").

Drug and alcohol addictions with diagnoses of mental illness were high among the homeless population when compared to the general population. Studies have shown that $31 \%$ of homeless individuals using substances also suffer from mental illness, with the most common being schizophrenia, depression, personality disorders and anxiety disorders (Burt, 2001). Homelessness among the mentally ill population was often due to lack of access to appropriate care (Wolfe, 2014).

Mental illness among the homeless is a public health issue. Healthy People 2020 identified mental health disparities among the homeless as one of their goals-- "Increase the proportion of homeless adults with mental health problems who receive mental health services" ("Mental Health and Mental Disorders", 2017).

Mental illness is the third leading cause of homelessness in America, and these individuals are more likely to remain homeless for a long time (Domenici, 2011). Individuals who were homeless for a long time and disabled are characterized as chronically homeless individuals (HUD, 2016).

Chronically homeless persons are at a higher risk for not receiving appropriate mental healthcare. According to a study on Specialty Mental Healthcare Among Homeless Individuals with SMI, three-fifths of persons with "severe mental illness did not receive specialty mental healthcare" within a 12 months' span. Receiving specialty mental healthcare was associated with income, race, and insurance (McAlpine, 2000).

Despite the negative views of deinstitutionalization, more and more studies supported the fact that segregated care was not a better option. Community care can provide appropriate services to mentally ill individuals without the need of institutionalization (McDaid and Thornicroft, 2005). Mississippi has 15 Community Mental Health Centers (CMHCs), and most of these CMHCs has Programs of Assertive Community Treatment (PACT) teams and/or peer case managers through the Cooperative Agreement to Benefit Homeless Individuals (CABHI) grants (Department of Mental Health Announces Housing Initiative, 2017). Several of the regional and community mental health centers were responsible for providing care to the rural areas. The large coverage areas of mental health centers lead to issues with access to services especially among the homeless population ("Mental Health in Mississippi: Analysis and Recommendations", 2014).

The cost of hospitalization, medical treatment, incarceration, police intervention, and emergency shelter expenses combine to make a hefty cost for taxpayers. It causes taxpayers about $\$ 40,000$ a year for each unhoused homeless person (Moorhead, 2012). In the fiscal year 2015, Mississippi Department of Mental Health spent $\$ 202.5$ million on the state institutional mental health hospitals (United States of America v. State of Mississippi). However, supportive housing with accommodations for the homeless with mental disabilities and other needed support services are more efficient and affordable for a community as a whole, then it is for a homeless person to remain unhoused and unsupported (National Alliance to End Homelessness, 2016).

Treatment for the mentally ill traditionally consisted of the individual being placed in an inpatient mental health hospital (asylums), and services provided at that hospital. Services consisted of on-site housing, medication, food, and treatment most times without a path for the individual to go back into their community. Mississippi currently has four state hospitals that provide these services and more; however, institutionalized care without a road to independence can lead to program dependence as was shown in a study by Stark (1994). In Stark study, homeless individuals who became depended on all the services provided by the shelter that, once released, they were not able to live in the community or provide/care for themselves. Individuals coming from institutional settings, where all services are delivered, are released to navigate the complex system of community services without a map and are what some may consider as helpless and unable to provide or fend for themselves. It is widely accepted that deinstitutionalization is a major contributor to the increase of homelessness and incarceration among the mentally ill (Maeseele, Bouverne-De Bie, and Roets, 2014).

Accessing community mental healthcare for a population who may not be connected to a community, or who may not know how to access services is difficult, if not impossible; however, it can improve their stability. The segregation of care provided to mentally ill individuals led to the investigation into Mississippi's appropriateness of care made available to the mentally ill population in December 2011. PEER, the Mississippi Legislature's Joint Committee on Performance Evaluation and Expenditure Review determined that "though the mental health environment in the United States has dramatically changed from an institutional-based system to a communitybased system in recent years, Mississippi's mental health system has not reflected the shift in delivery methods" (United States of America v. State of Mississippi, 2016). 
The aim of this study is to examine the prevalence of mental disorders in the homeless population in Mississippi. This study also investigated whether there is a relationship between mental disorders and mental health service utilization. The focus of this study was on homeless individuals who demographic, health information, and healthcare status was collected and stored in MUTEH's HMIS database.

\section{METHODOLOGY}

A total of 4326 people participated in the Homeless Programs that used MUTEH's HMIS database for one year. The data was obtained from HMIS database of initial screenings for homeless people living in Mississippi. The final population size consisted of 3375 homeless adults. Homeless Programs is the name of all programs that provide services to homeless individuals in Mississippi and uses MUTEH's HMIS to collect and store data on the homeless population they served. Homeless Programs incudes shelters, housing programs, outreach programs, community kitchens, community mental health programs, and all other programs that serve the homeless community and uses MUTEH's HMIS database.

Materials used in this study consisted of electronic HMIS records made by community providers that participate in MUTEH's HMIS database. HMIS has built in surveys, including a screening and intake survey designed to assess gender, mental health history, substance use and abuse history, history of homelessness, utilization of healthcare services, and other variables. The HMIS intake survey consists of four sections:

Section 1: Identifying information, demographic information, and homeless history

Section 2: Household income information

Section 3: Health related information

Section 4: Mental health related information

Personal identification codes that are unique to all individuals in HMIS were used to ensure that the population was unduplicated in this study. This study only analyzed information collected at the initial screening (first-time entry) into HMIS. All information collected was self-reported. MUTEH requires all HMIS participants to complete appropriate consents of information and information is only provided voluntarily to help connect individuals to the most suitable resources.

The independent variable in this study is mentally ill and the outcome variable was the utilization of mental healthcare services, defined as being connecting and receiving care from mental health and/or substance abuse services. Other variables analyzed in this study includes gender, race, income, mental illness, substance abuse, Veteran status, and chronic homeless status. The data were analyzed using Statistical Analysis System (SAS). Statistical testing will consist of Pearson's Chi SQ, and Frequency tables, for receiving community care. These tests are appropriate to determine the relationship between variables.

The study was a cross-sectional survey and all information collected from HMIS was secondary data. Once approved by the Program Director, the researcher received permission to spend time with MUTEH to analyzing data in HMIS related to this research. This research is a collaboration with MUTEH. The Homeless Programs recruited the subjects used in this study. The information collected was once at intake to provide a cross-sectional study of the homeless population.

\section{RESULTS}

The participants included $42 \%$ females, $58 \%$ males, and one other/non-specific all between the ages of 18 and 87. Their demographics were as followed: 45\% Caucasian, 54\% African American, and 1\% other races (Asian, Indian, and Pacific Islander). Exclusions include individuals that were not in any of the Homeless Programs during 2016, individuals who did not meet the definition of homelessness, and individuals below18 years of age.

A total of 3375 homeless adults were evaluated in this study. Out of those identified as homeless, 1390 (41\%) reported that they have a mental illness, $\mathrm{P}=<.0001 *$; $638(19 \%)$ reported that they have a Server Mental Illness (SMI) $\mathrm{P}=<.0001 * ; 1000(30 \%)$ reported that they have a substance abuse issues $\mathrm{P}=0.0001 *$ (see Table 1 ).

A total of 215 homeless adults were classified as chronically homeless. Out of those identified as chronically homeless, $178(83 \%)$ reported that they have a mental condition, and $37(17 \%)$ did not have mental health issues. Among those who are not chronically homeless 1212 (38\%) had a mental condition, and 1945 (62\%) did not. We may conclude that there is a significant relationship between being Chronically Homeless and having a mental health problem, $\mathrm{P}<.0001 *$ (see Table 2). 
Table 1. Illness rates of homeless adults

\begin{tabular}{|c|c|c|c|c|}
\hline & & \multicolumn{2}{|c|}{ Homeless } & \multirow{2}{*}{ Chi-square p-value } \\
\hline & & $\mathbf{N}$ & $\%$ & \\
\hline \multirow{2}{*}{ Mental } & Yes & 1390 & $41.22 \%$ & \multirow{2}{*}{$<.0001^{*}$} \\
\hline & $\mathrm{No}$ & 1982 & $58.78 \%$ & \\
\hline \multirow{2}{*}{ SMI or dual diagnose } & Yes & 638 & $18.92 \%$ & \multirow{2}{*}{$<.0001 *$} \\
\hline & $\mathrm{No}$ & 2734 & $81.08 \%$ & \\
\hline \multirow{2}{*}{ Substance } & Yes & 1000 & $29.66 \%$ & \multirow{2}{*}{$<.0001 *$} \\
\hline & $\mathrm{No}$ & 2372 & $70.34 \%$ & \\
\hline
\end{tabular}

Table 2. Mental condition versus chronically homelessness

\begin{tabular}{|c|c|c|c|c|c|c|}
\hline & & \multicolumn{2}{|c|}{ Yes Chronically Homeless } & \multicolumn{2}{|c|}{ No Chronically Home } & \multirow{2}{*}{$\begin{array}{c}\text { Chi-square } \mathrm{p}- \\
\text { value }\end{array}$} \\
\hline & & $\mathbf{N}$ & $\%$ & $\mathbf{N}$ & $\%$ & \\
\hline \multirow{2}{*}{ Mental } & Yes & 178 & $82.79 \%$ & 1212 & $38.39 \%$ & \multirow{2}{*}{$<.0001 *$} \\
\hline & No & 37 & $17.21 \%$ & 1945 & $61.61 \%$ & \\
\hline
\end{tabular}

Table 3. Mental conditions versus receiving services

\begin{tabular}{|c|c|c|c|c|c|c|}
\hline & & \multicolumn{2}{|c|}{ Receiving MH Services } & \multicolumn{2}{|c|}{ No MH Services } & \multirow{2}{*}{$\begin{array}{c}\text { Chi-square p- } \\
\text { value }\end{array}$} \\
\hline & & $\mathbf{N}$ & $\%$ & $\mathbf{N}$ & $\%$ & \\
\hline \multirow{2}{*}{ Mental } & Yes & 912 & $100 \%$ & 478 & $19.45 \%$ & \multirow{2}{*}{$<.0001 *$} \\
\hline & No & 0 & & 1982 & $80.57 \%$ & \\
\hline \multirow{2}{*}{ All mental } & Yes & 1221 & $67.05 \%$ & 600 & $32.77 \%$ & \multirow{2}{*}{$<.0001^{*}$} \\
\hline & No & 0 & & 1552 & $72.15 \%$ & \\
\hline \multicolumn{7}{|c|}{ Substance Services } \\
\hline \multirow{2}{*}{ Substance } & Yes & 559 & $100 \%$ & 441 & $15.68 \%$ & \multirow{2}{*}{$<.0001^{*}$} \\
\hline & No & 0 & & 2372 & $84.32 \%$ & \\
\hline
\end{tabular}

Table 4. Receiving services versus some general variables

\begin{tabular}{|c|c|c|c|c|c|c|}
\hline & & \multicolumn{2}{|c|}{ Receiving MH Services } & \multicolumn{2}{|c|}{ No MH Services } & \multirow{2}{*}{$\begin{array}{c}\text { Chi-square p- } \\
\text { value }\end{array}$} \\
\hline & & $\mathbf{N}$ & $\%$ & $\mathbf{N}$ & $\%$ & \\
\hline \multicolumn{7}{|c|}{ Controlling for $\mathrm{MH}$ yes } \\
\hline \multirow{3}{*}{ Gender } & Male & 475 & $52.08 \%$ & 310 & $64.85 \%$ & \multirow{3}{*}{$<.0001 *$} \\
\hline & Female & 437 & $47.92 \%$ & 167 & $34.94 \%$ & \\
\hline & Transgender & 0 & $0 \%$ & 1 & $0.21 \%$ & \\
\hline \multirow{2}{*}{ Income } & Yes & 510 & $55.92 \%$ & 136 & $28.45 \%$ & \multirow{2}{*}{$<.0001 *$} \\
\hline & $\mathrm{No}$ & 402 & $44.08 \%$ & 342 & $71.55 \%$ & \\
\hline \multirow{2}{*}{ Veteran } & Yes & 254 & $27.85 \%$ & 77 & $16.11 \%$ & \multirow{2}{*}{$<.0001 *$} \\
\hline & No & 658 & $72.15 \%$ & 401 & $83.89 \%$ & \\
\hline \multirow{5}{*}{ Race } & Black & 483 & $48.03 \%$ & 188 & $39.33 \%$ & \multirow{5}{*}{$0.03^{*}$} \\
\hline & White & 464 & $50.88 \%$ & 286 & $59.83 \%$ & \\
\hline & Indian & 7 & $0.77 \%$ & 3 & $0.42 \%$ & \\
\hline & Asian & 1 & $0.11 \%$ & 1 & $0.21 \%$ & \\
\hline & Pacific Islander & 2 & $0.77 \%$ & 1 & $0.21 \%$ & \\
\hline \multirow{2}{*}{$\begin{array}{l}\text { Chronically } \\
\text { Homeless }\end{array}$} & Yes & 71 & $7.79 \%$ & 107 & $22.38 \%$ & \multirow{2}{*}{$<.0001 *$} \\
\hline & $\mathrm{No}$ & 841 & $92.21 \%$ & 371 & $77.62 \%$ & \\
\hline
\end{tabular}

Among the homeless who were mentally ill, only 19\% did not receive mental health services $\mathrm{P}=<.0001 *$. Among the homeless who has any mental illness (mental and/or substance), 33\% does not receive mental health or substance services, and 67\% does $\mathrm{P}<.0001 *$. Among the homeless who have substance issues, $16 \%$ does not receive substance abuse care $\mathrm{P}<.0001 *$. It's concluded that there is a significant relationship between mental illness (mental health and/or substance) and utilizing mental health/substance services $\mathrm{P}=<.0001 *$. The relationship between mental illness and utilization of care is provided in Table 3.

After controlling for all homeless individuals who reported having a mental health condition and comparing their utilization of services among the different variables, there has shown to be some significant relationships.

Among males, $52 \%$ receive mental healthcare. Males were more likely to receive mental healthcare than females (52\%-48\%) at $\mathrm{P}<.0001 *$. Among Blacks, 48\% received mental healthcare. Among those who were White, 51\% received care. Among Indians (0.77\%) received care. Among Asians (0.11\%) received care. Among Pacific Islanders there were $0.77 \%$ that received care. Receiving Mental healthcare is highest among whites $(\mathrm{P}=0.03)$. Furthermore, 28\% Veterans, received mental healthcare, and non-veterans (72\%) received care, and $84 \%$ did not receive care. We conclude that there is a significant relationship between mental healthcare and not being a Veteran, 
$\mathrm{P}<.0001$. Among those with income, 56\% receive mental healthcare. Among those with no income 44\%. We conclude that there is a significant relationship between mental healthcare and income, $\mathrm{P}<.0001^{*}$. Among those who are chronically homeless, $8 \%$ receive mental healthcare, and $22 \%$ does not receive care. Among those who are not chronically homeless, $92 \%$ receive care. We conclude that there is a significant relationship between mental healthcare and not being chronically homeless, $\mathrm{P}<.0001 *$. The relationship between mental illness and utilization of care among the different variables are provided in Table 4.

\section{DISCUSSION}

This study analyzed the utilization of mental healthcare services among homeless individuals in Mississippi and found mental illness was strongly related to chronic homelessness. Further analysis of the data indicated that there was a significant relationship between mental illness and utilization of mental healthcare among the homeless population. The use of mental healthcare was highest among the following groups white males. However, the study also revealed that $92 \%$ of mentally ill chronically homeless individuals are not utilizing mental healthcare $(\mathrm{P}$ $<.0001 *)$.

The data showed a gap in healthcare services utilization among the chronically homeless who are also mentally ill. In this study, the gap in mental health service utilization was only significant among the chronically homeless. The results indicated that non-chronically homeless individuals in Mississippi utilizes mental healthcare.

There were a few disadvantages to this study that affected the results. One disadvantage is the data collected was self-reported, and individuals may feel that they have to be untruthful. The second, data was collected based off a point-in-time survey and individuals only had to indicated "yes" to receiving care without considering if it was continued care or a one-time hospital visit. Future studies on the mentally ill homeless population can help determine the appropriateness of care. Using the information gain from this study, a future study will be conducted on homeless individuals coming out of state psychiatric hospitals who are receiving community housing and mental health services and their frequency to the emergency room, psychiatric hospitals, jails, and their level of risky behavior. This study will help determine how effective and appropriate the care being provided is to increasing community stability.

\section{CONCLUSION}

This study examined the utilization of mental healthcare services among the homeless population and found that chronically homeless individuals were particularly strongly associated with having a mental disorder and not utilizing mental healthcare. The gap in mental healthcare utilization was only observed among the chronically homeless. Increased outreach to the chronically homeless population and providing innovative methods of care like mobile mental health clinics can increase mental healthcare utilization among this population. Providing appropriate follow-up care to individuals released from institutionalization into homelessness can increase the utilization of mental healthcare services among the mentally ill homeless population. Despite a relatively high number of individuals indicating that they utilized mental healthcare, treatment including medication and followup care is insufficient among this population.

\section{ACKNOWLEDGMENT}

The Author would like to thanks, Professor Mustafa Z. Younis for his assistant and comments on this manuscript and to anonymous reviewers.

\section{REFERENCES}

Burt, M.R. (2001). What Will It Take To End Homelessness?. Urban Institute. [online] Available at: http://webarchive.urban.org/UploadedPDF/end_homelessness.pdf

Caught Up in the Action: Mississippi's "5 in 5" Plan Institute for Disability Studies The University of Southern Mississippi. (n.d.). [online] Available at: https://www.aucd.org/meetings/186/13131/RYoung\%202013\%20 AUCD\%20Conference\%20Poster.pdf [Accessed Apr. 2017].

Chronic Homelessness. (2016, January). [online] Available at: https://www.hudexchange.info/homelessnessassistance/resources-for-chronic-homelessness/ [Accessed 28 Nov. 2016]. 
Department of Mental Health Announces Housing Initiative. (2017, April 13). [online] Available at: http://www.dmh.ms.gov/department-of-mental-health-announces-housing-initiative/ [Accessed 15 Apr. 2017].

Domenici, P. (2011, February). Homeless Mentally Ill Facts, Figures and Anecdotes. [online] Available at: http://mentalillnesspolicy.org/consequences/homeless-mentally-ill.html [Accessed 3 Nov. 2016].

Facts About Mental Illness. (n.d.). [online] Available at: http://www.namissw.org/mental_health/facts.htm [Accessed 31 May 2017].

Homeless Management Information System. (n.d.). [online] Available at: https://www.hudexchange.info/programs/hmis/ [Accessed 14 Feb. 2017].

Homelessness and Housing. (2016, March). [online] Available at: https://www.samhsa.gov/homelessness-housing

Isaac, R.J. and Armat, V.C. (1990). Madness in the Streets: How Psycbiatry and the Law Abandoned the Mentally Ill. Treatment Advocacy Center.

Justice Department Sues Mississippi for Discriminating Against Adults with Mental Illness. (2016, August 11). [online] Available at: https://www.justice.gov/opa/pr/justice-department-sues-mississippi-discriminatingagainst-adults-mental-illness [Accessed 7 Dec. 2016].

Maeseele, T., Bouverne-De Bie, M. and Roets, G. (2014, February 10). Between Institutional Inclusion and Invisibility? The Case of Flemish Homelessness Care. Australian Social Work, 67(4), pp. 537-553. https://doi.org/10.1080/0312407X.2014.931978

McAlpine, D. and Mechanic, D. (2000). Utilization of specialty mental healthcare among persons with severe mental illness: the roles of demographics, need, insurance, and risk. Health Services Research, 35(1), 2nd ser., pp. 277-292. https://doi.org/10.1075/ps.5.3.02chi.audio.2f

McDaid, D. and Thornicroft, G. (2005). Mental health II Balancing institutional and community-based care. European Observatory on Health Systems and Policies: World Health Organization. [online] Available at: http://www.enil.eu/wp-content/uploads/2012/07/Mental-Health-II_Balancing-institutional-andcommunity-based-care.pdf

Mental Health and Mental Disorders. (2017, July 20). [online] Available at: https://www.healthypeople.gov/2020/topics-objectives/topic/mental-health-and-mentaldisorders/objectives [Accessed 21 Jul. 2017].

Mental Health By The Numbers. (2017). [online] Available at: https://www.nami.org/Learn-More/MentalHealth-By-the-Numbers [Accessed Jul. 2017].

Mental Health in Mississippi: Analysis and Recommendation (Rep.). (2014). Harvard Law School Mississippi Delta Project.

Mental Illness. (2016). [online] Available at: https://www.cdc.gov/mentalhealth/basics/mental-illness.htm [Accessed 5 Dec. 2016].

Moorhead, M. (2012, March 12). HUD secretary says a homeless person costs taxpayers $\$ 40,000$ a year. [online] Available at: http://www.politifact.com/truth-o-meter/statements/2012/mar/12/shaun-donovan/hud-secretary-sayshomeless-person-costs-taxpayers/ [Accessed 5 Jun. 2016].

National Alliance to End Homelessness. (2016). Health Care. [online] Available at: http://www.endhomelessness.org/pages/mental_physical_health [Accessed 5 Jun. 2016].

Rossi, P.H. (1990). The old homeless and the new homelessness in historical perspective. American Psychologist, 45, pp. 954-959. https:// doi.org/10.1037/0003-066X.45.8.954

Stark, L.R. (1994). The Shelter as "Total Institution": An Organizational Barrier to Remedying Homelessness. American Behavioral Scientist, 37(4), pp. 553-562. https://doi.org/10.1177/0002764294037004008

Torrey, E., MD. (2005, May 10). Deinstitutionalization: A Psychiatric "Titanic". [online] Available at: http://www.pbs.org/wgbh/pages/frontline/shows/asylums/special/excerpt.html [Accessed 1 Dec. 2016].

United States of America v. State of Mississippi (August, 2016). [online] Available at: https://www.justice.gov/opa/file/883741/download

United States' Investigation of the State of Mississippi's Service System for Persons with Mental Illness and Developmental Disabilities (Southern District of Mississippi North Division August 11, 2016).

Wolfe, A. (2014, August 27). Left to Fend: The State's Mental Health Failure. Jackson Free Press. [online] Available at: http://www.jacksonfreepress.com/news/2014/aug/27/left-fend-states-mental-health-failure/ [Accessed Dec. 2016].

World Health Organization (2001). The world health report 2001 - Mental Health: New Understanding, New Hope. 